\title{
World kidney day 2018; chronic kidney disease and women's health
}

\author{
Masoud Amiri* \\ Department of Epidemiology and Biostatistics, Shahrekord University of Medical Sciences, Shahrekord, Iran
}

\section{A R T I C L E I N F O}

Article Type:

Mini-Review

\section{Article History:}

Received: 20 September 2017

Accepted: 4 November 2017

Published online: 8 December 2017

Keywords:

Kidney

Chronic kidney disease

Pregnancy

Pre-pregnancy counselling

\begin{abstract}
A B S T R A C T
In the 13th anniversary of World Kidney Day campaign in 2018, the focus is on kidney diseases and chronic kidney disease (CKD) among women. The relatively higher rates of hypertension, diabetes, overweight and obesity among women could make them vulnerable to progress CKD more than men. In addition, pregnant women and their fetuses with CKD are indeed prone to higher morbidity and mortality. One of the best methods to prevent adverse maternal and fetal outcomes would be pre-pregnancy counselling for women with CKD to aware them about the risks of their potential pregnancy and related factors such as proteinuria, hypertension and teratogenic medication. The control of hypertension might also be the best intervention for these patients.
\end{abstract}

Implication for health policy/practice/research/medical education:

Primary prevention of chronic kidney disease (CKD) in women, especially during pregnancy, results in the control of obesity, type 2 diabetes and hypertension as well as lifestyle corrections like reduction of weight, sporting and a healthy diet. In fact, the control of hypertension, proteinuria, hyperlipidemia and smoking are the most important current interventions. Early case finding of CKD among women, especially pregnant ones, is also very important. One of the best methods to prevent adverse maternal and fetal outcomes would be pre-pregnancy counselling for women with CKD to aware them about the risks of their potential pregnancy and related factors such as proteinuria, hypertension and teratogenic medication. For secondary prevention, it seems that the control of hypertension is the best intervention. There are also some methods to predict CKD among people such as algorithms that have been designed to predict the individual's five-year risk of being diagnosed.

Please cite this paper as: Amiri M. World kidney day 2018; chronic kidney disease and women's health. J Renal Inj Prev. 2018;7(3):136-138. doi: 10.15171/jrip.2018.34.

\section{Introduction}

The proportion of patients having chronic kidney disease (CKD) and further end-stage renal disease (ESRD) are increasing worldwide with an important burden on global resources of health care $(1,2)$. Their future continuous increasing might be due to the ageing of population (3) as well as increasing burden of type 2 diabetes (4) all over the world. Epidemiological studies have reported several factors that may affect on the starting and progress of CKD which can be divided into two main categories including risk factors (causal) and risk markers (related to CKD in the absence of proven causal relationships) (2). In addition, there are some susceptibility factors such as: genetic (5), race (6), infant malnutrition and low birth weight (7) and elderly (3). Moreover, it has been found that diabetes, hypertension, smoking, obesity and hyperlipidemia can be considered as risk factors of progressing of CKD in the general population $(8,9)$. Type 2 diabetes is one of the most important leading causes of CKD (10). Moreover, anemia is prevalent among diabetic patients with CKD due to deficiency of iron and erythropoietin (11). Among CKD patients, the most prevalent causes of death would be cancer, cardiovascular diseases and infections (12).

\section{Materials and Methods}

For this mini-review, we used a variety of sources including Web of Science, PubMed, Embase, Scopus and directory of open access journals (DOAJ). The search 
was performed by using combinations of the following keywords and or their equivalents; chronic kidney disease, diabetes mellitus, hypertension, acute kidney injury, type 2 diabetes, end-stage renal disease, kidney, pregnancy, pre-pregnancy counselling, nutritional status, Chronic renal failure, women's health and malnutrition

\section{World kidney day 2018}

World kidney day will emphasis on the kidney and women's health in 2018. As a global health campaign, world kidney day, the second Thursday of March each year, is focusing on one special topic related to kidney, to increase the awareness of world people about the kidney diseases (especially CKD). In the 13th anniversary of this campaign in 2018, this day will focus on kidney diseases and CKD among women. The relatively higher rates of hypertension (13), diabetes (14), overweight and obesity (15) among women could make them vulnerable to progress CKD more than men. In addition, women with CKD may have sexual dysfunction such as menstrual abnormalities and decreasing fertility (16). In fact, CKD in women is usually followed by fertility and menstrual disorders because of kidney dysfunction $(17,18)$. There is also some evidence that the female gender could be considered as a risk factor for dialysis access failure (19). In addition, diabetic women may have a higher risk of obtaining CKD compared to men which cannot be completely explained by considering different CKD risk factors, diabetes self-care or depression (20). Type 2 diabetes, as a leading cause of CKD is very important; thus, conducting some strategies for preventing of CKD in these patients may include optimization of glycemic level, blood pressure control and appropriate medications (20). Each pregnant woman has a substantial hormonal and hemodynamic changes which can affect kidney function, especially in preeclampsia (21). Almost $4 \%$ of women at childbearing age may have CKD (22). Pregnant women with CKD and their fetuses are indeed prone to higher morbidity and mortality (23). In addition, the substantial influence of pregnancy in women with CKD is referred to the degree of kidney impairment and having hypertension (24). Moreover, the pregnancy complications for these patients might be prematurity, spontaneous abortion, intrauterine growth retardation, kidney disease flare and preeclampsia (25). The adverse effects of CKD on pregnant women, and related risk of adverse outcomes for mother and fetus, has confirmed in a systematic review study in 2011 (26). It could be better that all pregnant women with $\mathrm{CKD}$ will be considered as high-risk pregnancies. Therefore, the measurement of proteinuria during pregnancy should be applied (27). In addition, it has been proved that pregnant women with mild renal impairment, normal blood pressure and no (or little) proteinuria may have good childbearing (28). It has also been reported that pregnancy after transplantation has no special complication, as long as kidney function is fine (29). Moreover, kidney biopsy in pregnant women is an appropriate method for early detection of asymptomatic patients (30).

It is worth to be an emphasis that the importance of CKD among women should not result in neglecting CKD among men. Moreover, although CKD is more common among women. However, it is more severe among men (31). In addition, although CKD is more prevalent among women, the incidence of ESRD is higher among men which indicates that the progression rate of renal dysfunction may be faster among men than women (31).

\section{Conclusion}

As a conclusion, primary prevention of CKD in women, especially during pregnancy, would be the control of obesity and type 2 diabetes and hypertension as well as lifestyle corrections like reduction of weight, sporting and a healthy diet. In fact, the control of hypertension, proteinuria, hyperlipidemia and smoking are the most important current interventions. Early case finding of CKD among women, especially pregnant ones, is also very important. One of the best methods to prevent adverse maternal and fetal outcomes would be pre-pregnancy counselling for women with CKD to aware them about the risks of their potential pregnancy and related factors such as proteinuria, hypertension and teratogenic medication (32). For secondary prevention, it seems that the control of hypertension is the best intervention (33). There are also some methods to predict CKD among people such as algorithms that have been designed to predict the individual's five-year risk of being diagnosed (34). A laboratory measurement is not necessary by these algorithms which will result in their ability to be suitable to use in the time that the information is not provided.

\section{Author's contribution}

MA is the single author of the paper.

\section{Conflicts of interest}

The author declares no conflict of interest.

\section{Ethical considerations}

Ethical issues (including plagiarism, data fabrication, double publication) have been completely observed by the author.

\section{Funding/Support}

None.

\section{References}

1. Lysaght MJ. Maintenance dialysis population dynamics: current trends and long-term implications. J Am Soc Nephrol. 2002;13 Suppl 1:S37-40.

2. Meguid El Nahas A, Bello AK. Chronic kidney disease: the global challenge. Lancet. 2005;365:331-40.

3. United States Renal Data System. Annual data report: incidence and prevalence of ESRD. Am J Kidney Dis. 2003;42:S37-173.

4. King $\mathrm{H}$, Aubert RE, Herman WH. Global burden of 
diabetes, 1995-2025: prevalence, numerical estimates, and projections. Diabetes Care. 1998;21:1414-31.

5. Bergman S, Key BO, Kirk KA, Warnock DG, Rostant SG. Kidney disease in the first-degree relatives of AfricanAmericans with hypertensive end-stage renal disease. Am J Kidney Dis. 1996;27:341-6.

6. Buck K, Feehally J. Diabetes and renal failure in Indo-Asians in the UK: a paradigm for the study of disease susceptibility Nephrol Dial Transplant. 1999;12:1555-57.

7. Brenner BM, Chertow GM. Congenital oligonephropathy and the etiology of adult hypertension and progressive renal injury. Am J Kidney Dis. 1994;23:171-5.

8. Iseki K. The okinawa screening program. J Am Soc Nephrol. 2003;14:S127-30.

9. Schaeffner ES, Kurth T, Curhan GC, Glynn RJ, Rexrode $\mathrm{KM}$, Baigent $\mathrm{C}$, et al. Cholesterol and the risk of renal dysfunction in apparently healthy men. J Am Soc Nephrol. 2003;14:2084-91.

10. Herzog CA, Mangrum JM, Passman R. Sudden cardiac death and dialysis patients. Semin Dial. 2008;21:300-7. doi: 10.1111/j.1525-139X.2008.00455.

11. Vlagopoulos PT, Tighiouart H, Weiner DE, Griffith J, Pettitt D, Salem DN, et al. Anemia as a risk factor for cardiovascular disease and all-cause mortality in diabetes: the impact of chronic kidney disease. J Am Soc Nephrol. 2005;16:3403-10.

12. John R, Webb M, Young A, Stevens PE. Unreferred chronic kidney disease: a longitudinal study. Am J Kidney Dis. 2004;43:825-35.

13. Jafar TH, Stark PC, Schmid CH, Landa M, Maschio G, de Jong PE, et al. Progression of chronic kidney disease: the role of blood pressure control, proteinuria, and angiotensinconverting enzyme inhibition: a patient-level meta-analysis. Ann Intern Med. 2003;139:244-52.

14. Adler AI, Stevens RJ, Manley SE, Bilous RW, Cull CA, Holman RR, et al. Development and progression of nephropathy in type 2 diabetes: the United Kingdom Prospective Diabetes Study (UKPDS 64). Kidney Int. 2003;63:225-32.

15. de Jong PE, Verhave JC, Pinto-Sietsma SJ, Hillege HL, group Ps. Obesity and target organ damage: the kidney. Int J Obes Relat Metab Disord. 2002;26 Suppl 4:S21-4.

16. Palmer BF. Sexual dysfunction in men and women with chronic kidney disease and end-stage kidney disease. Adv Ren Replace Ther. 2003;10:48-60.

17. Ahmed SB, Ramesh S. Sex hormones in women with kidney disease. Nephrol Dial Transplant. 2016;31:1787-95.

18. Strippoli GF, Vecchio M, Palmer S, De Berardis G. Sexual dysfunction in women with ESRD requiring hemodialysis. Clin J Am Soc Nephrol. 2012;7:974-81. doi: 10.2215/ CJN.12601211.

19. Pounds LL, Teodorescu VJ. Chronic kidney disease and dialysis access in women. J Vasc Surg. 2013;57:49S-53S e1.

20. Yu MK, Katon W, Young BA. Associations between sex and incident chronic kidney disease in a prospective diabetic cohort. Nephrology (Carlton). 2015;20:451-8. doi: 10.1111/ nep.12468.

21. Maynard SE, Thadhani R. Pregnancy and the kidney. J Am Soc Nephrol. 2009;20(1):14-22.

22. Fischer MJ. Chronic kidney disease and pregnancy: maternal and fetal outcomes. Adv Chronic Kidney Dis. 2007;14:132-45.

23. Fischer MJ, Lehnerz SD, Hebert JR, Parikh CR. Kidney disease is an independent risk factor for adverse fetal and maternal outcomes in pregnancy. Am J Kidney Dis. 2004;43:415-23.

24. Lightstone L. Kidney disease and pregnancy. Medicine. 2015;43:550-5.

25. Smyth A, Radovic M, Garovic VD. Women, kidney disease, and pregnancy. Adv Chronic Kidney Dis. 2013;20:402-10.

26. Nevis IF, Reitsma A, Dominic A, McDonald S, Thabane L, Akl EA, et al. Pregnancy outcomes in women with chronic kidney disease: a systematic review. Clin J Am Soc Nephrol. 2011;6:2587-98. doi: 10.2215/CJN.10841210.

27. Eknoyan G, Hostetter T, Bakris GL, Hebert L, Levey AS, Parving $\mathrm{HH}$, et al. Proteinuria and other markers of chronic kidney disease: a position statement of the national kidney foundation (NKF) and the national institute of diabetes and digestive and kidney diseases (NIDDK). Am J Kidney Dis. 2003;42:617-22.

28. Jungers P, Houillier P, Forget D, Labrunie M, SkhiriH, Giatras I, et al. Influence of pregnancy on the course of primary chronic glomerulonephritis. Lancet. 1995;346:1122-4.

29. Framarino Dei Malatesta M, Rossi M, Rocca B, Iappelli M, Poli L, Piccioni MG, et al. Fertility following solid organ transplantation. Transplant Proc. 2007;39:2001-4.

30. Day C, Hewins P, Hildebrand S, Sheikh L, Taylor G, Kilby $\mathrm{M}$, et al. The role of renal biopsy in women with kidney disease identified in pregnancy. Nephrol Dial Transplant. 2008;23:201-6.

31. Goldberg I, Krause I. The role of gender in chronic kidney disease. EMJ. 2016;1:58-64.

32. Wiles KS, Bramham K, Vais A, Harding KR, Chowdhury P, Taylor CJ, et al. Pre-pregnancy counselling for women with chronic kidney disease: a retrospective analysis of nine years' experience. BMC Nephrol. 2015;16:28. doi: 10.1186/ s12882-015-0024-6.

33. Bakris GL, Williams M, Dworkin L, Elliott WJ, Epstein $\mathrm{M}$, Toto $\mathrm{R}$, et al. Preserving renal function in adults with hypertension and diabetes: a consensus approach. National Kidney Foundation Hypertension and Diabetes Executive Committees Working Group. Am J Kidney Dis. 2000;36:646-61.

34. Hippisley-Cox J, Coupland C. Predicting the risk of chronic kidney disease in men and women in England and Wales: prospective derivation and external validation of the QKidney Scores. BMC Fam Pract. 2010;11:49. doi: 10.1186/1471-2296-11-49.

Copyright (C) 2018 The Author(s); Published by Nickan Research Institute. This is an open-access article distributed under the terms of the Creative Commons Attribution License (http://creativecommons.org/licenses/by/4.0), which permits unrestricted use, distribution, and reproduction in any medium, provided the original work is properly cited. 